\title{
Vagal Nerve Stimulation: Is It Effective in Children with Dravet Syndrome?
}

\author{
Deepa Sirsi ${ }^{1} \quad$ Muna Khan ${ }^{1} \quad$ Susan T. Arnold ${ }^{1}$ \\ ${ }^{1}$ Division of Pediatric Neurology, University of Texas Southwestern \\ Medical Center, Dallas, Texas, United States \\ J Pediatr Epilepsy 2016;5:7-10.
}

\begin{abstract}
Address for correspondence Deepa Sirsi, MD, Department of Pediatric Neurology, University of Texas Southwestern Medical Center, 5323, Harry Hines Blvd, Dallas, TX 75390, United States (e-mail: deepa.sirsi@utsouthwestern.edu).
\end{abstract}

\begin{abstract}
Keywords

- Dravet syndrome

- vagal nerve stimulation

- intractable epilepsy

Treatment of Dravet syndrome with anti-seizure medications is challenging and frequently disappointing in early childhood. Nonpharmacologic treatments for epilepsy including ketogenic diet, corpus callosotomy, and vagal nerve stimulation (VNS) are considered and used for management of medically refractory epilepsy. In this series, we report our experience with VNS in eight children with Dravet syndrome. Mean age at VNS implantation was 6.2 years. Duration of treatment with VNS ranged from 2 to 13 years. When compared with baseline, four of eight children had a 50 to $75 \%$ reduction in seizure frequency or duration. Four children had no significant improvement in seizures after VNS. The device was well tolerated in all patients without significant complications.
\end{abstract}

\section{Introduction}

Dravet syndrome is a rare childhood epilepsy syndrome with an incidence of 1 in 40,000 births. ${ }^{1}$ Clinically, this syndrome is characterized by onset of recurrent febrile and afebrile seizures during the first year of life in a previously normal infant. Seizures are typically febrile, hemiclonic, or generalized, and are often prolonged with status epilepticus. Subsequently, myoclonic seizures, absence, and focal seizures appear between the ages of 1 and 5 years. ${ }^{2}$ Seizures can be provoked by slight temperature variations such as baths and physical exercise without true fever. Epilepsy is treatment resistant, and developmental delays are noted to occur in most children to some degree. ${ }^{2}$ SCNIA mutations have been demonstrated in $\sim 85 \%$ of patients with Dravet syndrome. ${ }^{3}$

Status epilepticus, one of the core clinical manifestations of this condition, has been noted to be associated with developmental impairments. ${ }^{1,4}$ In addition, onset of absence seizures and myoclonic seizures early in life has been associated with worse cognitive outcome. ${ }^{5}$ There is a high mortality rate of 15 to $20 \%$ before the third decade of life $e^{6}$ in patients with Dravet syndrome due to status epilepticus and sudden unexpected death in epilepsy patients (SUDEP).
Prevention of status epilepticus and attempts at better control of absence and myoclonic seizures may influence developmental outcome. ${ }^{4}$ However, treatment and control of epilepsy in Dravet syndrome is challenging. Although, antiseizure medications (ASMs) such as topiramate ${ }^{7}$ and combinations such as valproic acid, clobazam, and stiripentol ${ }^{8}$ are effective at controlling seizures in some patients, pharmacoresistant epilepsy is common. Stiripentol is not available in many countries, including the United States. Nonpharmacologic treatments for epilepsy including ketogenic diet, corpus callosotomy, and vagal nerve stimulation (VNS) are considered and used for management of medically refractory epilepsy. ${ }^{9}$ VNS does not carry the burden of cognitive and behavioral side effects which are common with antiepileptic medications. VNS can also improve quality of life and neuropsychologic performance. ${ }^{10}$ In children with Dravet syndrome who have a known predilection to cognitive decline, ${ }^{8}$ polytherapy with ASMs likely compounds the inherent neurocognitive impairments. ${ }^{11}$

Literature review revealed limited information to address the effectiveness of VNS in Dravet syndrome patients. There was only one case series with eight patients identified on PubMed search which suggested that VNS was effective in

Copyright $\odot 2016$ by Georg Thieme Verlag KG, Stuttgart · New York
DOI http://dx.doi.org/ 10.1055/s-0035-1567851. ISSN 2146-457X. 
controlling seizures in $50 \%$ of their patients. ${ }^{12}$ Caraballo reported on nonpharmacologic treatments for Dravet syndrome and two of three children with Dravet syndrome in his experience had 50 to $74 \%$ improvement in seizures with VNS therapy. ${ }^{9}$ Thus, the number of published Dravet syndrome patients who received VNS for intractable epilepsy is limited to 11 .

The purpose of this study is to analyze our data for the experience of VNS in Dravet syndrome. Children with this syndrome have a catastrophic childhood epilepsy syndrome with frequent status epilepticus, limited treatment options, and high SUDEP rates. VNS, if effective, may provide a nonmedication treatment option for seizure control. This may improve lifespan and quality of life by decreasing episodes of seizures, status epilepticus, and provide an opportunity to reduce ASM doses.

\section{Methods}

The local institutional board approved the study and informed consent was waived by the institutional review board due to retrospective nature of the study.

\section{Patient Selection}

Consecutive patients with Dravet syndrome were selected, who had received a VNS placement for treatment of intractable epilepsy between 2005 and 2014 at the Comprehensive Epilepsy Center, Children's Health in Dallas, Texas. Criteria for inclusion were intractable epilepsy, genetic and/ or clinical diagnosis of Dravet syndrome, and VNS placement for management of epilepsy.

Only patients with at least 1 -year follow-up were included.

\section{Definitions}

Intractable epilepsy was defined as failure of two tolerated and appropriately chosen ASMs. ${ }^{6}$ The diagnosis of Dravet syndrome was based on criteria described by Charlotte Dravet $^{2}$ and included onset in the first year of life of often prolonged febrile or afebrile seizures, onset of multiple other seizure types (myoclonic, atypical absences, and focal seizures) in the second to third year of life, and a slowing of developmental and cognitive skills.

\section{Patient Information}

Retrospective chart review was conducted to determine demographics, age at onset of seizures, febrile or afebrile seizures at onset, duration of epilepsy, and age at VNS implantation. SCN1A mutation testing results were also included, if available.

Efficacy of VNS for seizure control was assessed by reviewing (1) number of antiepileptic medications started before and after VNS implantation, (2) caregiver reports of number of seizures before and after VNS, and (3) episodes of status epilepticus. VNS settings for each patient including output current and duty cycle were also reviewed.

Anticipated surgical complications of VNS such as infection, bleeding, and vocal cord paresis were noted for during chart review. Stimulation-related adverse effects such as throat paresthesia, cough, dyspnea, voice alteration, and arrhythmias were recorded.

Formal scales for evaluation of cognition and behavior before and after VNS placement were not available for most patients, but subjective information reported by parents and caregivers about alertness, attention, language and communication, and behavioral changes was collected.

\section{Results}

There were eight children identified who met inclusion criteria of diagnosis of Dravet syndrome, intractable epilepsy, and VNS placement for intractable epilepsy.

\section{Clinical Features of Patients}

The clinical features of the patients are summarized in - Table 1. Seven were girls and one was a boy. One child was of mixed race, two African American, two Hispanic (Caucasian), and three were Caucasian. Seizure onset was at or before 6 months of age for all patients and seven had febrile status epilepticus at seizure onset. All eight children had medically intractable epilepsy which led to VNS placement. Age at intractability of epilepsy was 2 to 3 years. Patients had received trials of four to nine ASMs before VNS implantation. Patient 4 and 8 had also tried the ketogenic diet for 2 and 3 months at age 7 and 8 years, respectively. Diet was discontinued due to lack of efficacy and side effects in patient 4 and due to noncompliance in patient 8 . Seven of eight patients had SCN1A mutation testing done. Three patients had known or predicted disease-causing mutations (patient 8 had a diseasecausing whole gene deletion), and four patients had variants of unclear significance (likely disease causing based on software predictions). Testing was not done for one patient due to prohibitive cost. Due to the small group size of patients, we could not draw correlations of genetic mutations with response of seizures to VNS therapy. It was, however, interesting to note that patient 8 with a disease-causing whole gene deletion had the best seizure response with $>75 \%$ improvement in seizures.

\section{Vagal Nerve Stimulation Treatment and Seizure Outcome}

- Table 2 summarizes the VNS treatment and seizure response information. - Table 3 includes the VNS settings. Ages at VNS implantation ranged from 2 to 15 years (mean age was 6.2 years and median age was 7 years). The duration of followup after treatment with VNS ranged from 2 to 13 years with a mean of 5.8 years. VNS surgery was performed at our institution for five out of eight patients. Three patients had VNS implantations at outside institutions prior to being followed at our institution. Children who had the VNS implantation at our institution had no acute surgical complications and the three patients who had VNS placement at outside institutions had not reported any surgical complications. The VNS was either turned on prior to discharge or at first follow-up visit. The settings were ramped up every 2 to 3 weeks by $0.25-\mathrm{mA}$ stimulation intensity until they achieved improvement in seizures or reached settings of 2-mA stimulation intensity. Rapid cycling settings were initiated after this if seizure control remained suboptimal. 
Table 1 Clinical features

\begin{tabular}{|c|c|c|c|c|c|c|}
\hline Patient & Race & $\begin{array}{l}\text { Current } \\
\text { age (y) }\end{array}$ & Gender & SCN $1 A$ mutation & $\begin{array}{l}\text { Age at seizure onset, } \\
\text { febrile/afebrile }\end{array}$ & $\begin{array}{l}\text { Age at intractable } \\
\text { epilepsy (y) }\end{array}$ \\
\hline 1 & Mixed & 11 & $\mathrm{~F}$ & $\begin{array}{l}\text { Variant of unclear signifi- } \\
\text { cance, likely pathogenic, } \\
\text { de novo }\end{array}$ & 4 mo, febrile & 2 \\
\hline 2 & Caucasian & 13 & $\mathrm{~F}$ & Testing not done & 5 mo, febrile & 2.5 \\
\hline 3 & $\begin{array}{l}\text { African } \\
\text { American }\end{array}$ & 13 & $\mathrm{~F}$ & $\begin{array}{l}\text { Variant of unclear signifi- } \\
\text { cance, likely pathogenic, } \\
\text { de novo }\end{array}$ & 6 mo, febrile & 2 \\
\hline 4 & Caucasian & 13 & $\mathrm{~F}$ & $\begin{array}{l}\text { Predicted disease-associated } \\
\text { mutation frame shift, } 2 \mathrm{bp} \\
\text { duplication of AG }\end{array}$ & 4 mo, febrile & 3 \\
\hline 5 & $\begin{array}{l}\text { Hispanic } \\
\text { Caucasian }\end{array}$ & 10 & $\mathrm{~F}$ & $\begin{array}{l}\text { Known disease-associated } \\
\text { mutation }\end{array}$ & 4 mo, febrile & 2 \\
\hline 6 & Caucasian & 15 & $\mathrm{~F}$ & $\begin{array}{l}\text { Variant of unclear signifi- } \\
\text { cance, likely pathogenic, } \\
\text { de novo }\end{array}$ & 3 mo, febrile & 2 \\
\hline 7 & $\begin{array}{l}\text { Hispanic } \\
\text { Caucasian }\end{array}$ & 8 & $\mathrm{~F}$ & $\begin{array}{l}\text { Variant of unclear signifi- } \\
\text { cance, likely pathogenic, } \\
\text { de novo }\end{array}$ & 6 mo, febrile & 2.5 \\
\hline 8 & $\begin{array}{l}\text { African } \\
\text { American }\end{array}$ & 17 & $\mathrm{M}$ & $\begin{array}{l}\text { Disease-causing whole gene } \\
\text { deletion }\end{array}$ & 5 mo, afebrile & 2 \\
\hline
\end{tabular}

Table 2 VNS placement, ASM information before and after VNS, and seizure response to VNS

\begin{tabular}{|l|l|l|l|l|l|l|}
\hline Patient & $\begin{array}{l}\text { VNS placement } \\
\text { age (y) }\end{array}$ & $\begin{array}{l}\text { ASM } \\
\text { before VNS }\end{array}$ & $\begin{array}{l}\text { Current } \\
\text { ASM }\end{array}$ & $\begin{array}{l}\text { ASM } \\
\text { after VNS }\end{array}$ & $\begin{array}{l}\text { Duration of } \\
\text { follow-up (y) }\end{array}$ & Response of seizures \\
\hline 1 & 3 & 4 & 1 & 3 & 8 & 50 to 75\% improvement \\
\hline 2 & 7 & 8 & 3 & 4 & 6 & No significant improvement \\
\hline 3 & 7 & 9 & 3 & 2 & 6 & 50 to 75\% improvement \\
\hline 4 & 6 & 4 & 3 & 5 & 7 & No significant improvement \\
\hline 5 & 7 & 6 & 3 & 0 & 3 & $\begin{array}{l}\text { Decrease in seizure duration with no SE. } \\
\text { Seizure frequency unchanged }\end{array}$ \\
\hline 6 & 2 & 5 & 3 & 5 & 13 & No significant improvement \\
\hline 7 & 3 & 4 & 2 & 5 & 5 & No significant improvement \\
\hline 8 & 15 & 9 & 4 & 0 & 2 & $>75 \%$ improvement \\
\hline
\end{tabular}

Abbreviations: ASM, anti-seizure medication; SE, status epilepticus; VNS, vagal nerve stimulation.

Table 3 VNS settings

\begin{tabular}{|l|l|l|}
\hline Patient & $\begin{array}{l}\text { VNS output current } \\
(\mathrm{mA})\end{array}$ & $\begin{array}{l}\text { Duty cycle } \\
\text { (\% on time) }\end{array}$ \\
\hline 1 & 1.25 & $44 \%$ \\
\hline 2 & 2 & $29 \%$ \\
\hline 3 & 1.75 & $44 \%$ \\
\hline 4 & 2 & $29 \%$ \\
\hline 5 & 2 & $29 \%$ \\
\hline 6 & 2.25 & $44 \%$ \\
\hline 7 & 2 & $19 \%$ \\
\hline 8 & 2 & $16 \%$ \\
\hline
\end{tabular}

Abbreviation: VNS, vagal nerve stimulation.
Five of eight patients were at stimulation intensity of $2 \mathrm{~mA}$; patient 1 was at $1.25-\mathrm{mA}$, patient 3 at $1.75-\mathrm{mA}$, and patient 6 at 2.25-mA stimulation intensity. All eight patients were at rapid cycling settings with duty cycles (\% on time) ranging from 16 to $44 \%$. The stimulation intensity had to be decreased in patients 1 and 3 due to coughing and hoarseness, as they were titrated to higher duty cycle settings to achieve better seizure control. The device and settings were well tolerated in all patients.

When compared with baseline, four of eight children had either a more than $50 \%$ reduction in seizure frequency or decreased status epilepticus which resulted in reduced use of rescue medications, emergency room visits, intensive care unit admissions, and improved quality of life. Four children had no significant improvement in seizures after VNS. VNS 
was turned off for patient 1 around the time of anticipated battery replacement. Complex partial seizures recurred and VNS was turned back on with resumption of seizure control.

Battery was replaced for patients 1 and 6 after 8 to 9 years. Although the caregivers of patient 6 reported a less than 50\% improvement in seizures with VNS therapy, the improvement noted was considered significant enough to proceed with battery replacement after 8 years of VNS placement.

Although no formal scales for objective assessment of cognition and behavior were available during chart review, caregivers of patients 3 and 8 reported subjective improvement in alertness and interaction after VNS placement along with improved seizure control.

\section{Discussion}

Children with Dravet syndrome have severe childhood-onset epilepsy with frequent episodes of status epilepticus and medically intractable seizures. The seizures frequently do not respond to ASMs leading to multiple trials of medications and combinations of medications. Nonmedication treatment options such as ketogenic diet and VNS should be considered for these patients as has been suggested by other authors. ${ }^{9,12}$ Our experience with VNS in 8 children with Dravet syndrome shows good tolerability and was effective in $50 \%$ of patients in improving seizure control by more than $50 \%$ and/or decreasing episodes of status epilepticus which is consistent with the results published in two other studies that involved 11 patients. $^{9,12}$ Our study now nearly doubles the information available in literature on Dravet syndrome patients treated with VNS for intractable epilepsy.

The limitations of this study included its retrospective dataset, lack of information about response of individual seizure subtypes to VNS in each patient, and lack of objective data on cognitive and behavioral response to VNS therapy.

It has been suggested by a larger study involving 347 children with drug-resistant epilepsy that earlier treatment, before age 12 years, with VNS in children is more effective for seizure control ${ }^{13}$ but this type of subgroup analysis could not be performed in our patients due to small patient numbers. A larger prospective multicenter study will help determine this and if confirmed can lead to earlier treatment with VNS and decrease the burden of seizures and status epilepticus in Dravet syndrome patients.

The average age at VNS placement on our patients was 6.2 years. Seizure onset was at or before 6 months in all children and age at intractability of epilepsy was 2 to 3 years. This time lag between intractability of seizures and VNS placement could be due to delay in diagnosis of Dravet syndrome and due to lack of information about effectiveness of VNS in Dravet syndrome. Clinical screening and, if appropriate, genetic screening of infants who present with febrile status epilepticus for Dravet syndrome will decrease the delay in diagnosis and lead to appropriate aggressive management with medications and other treatment options.

It remains to be evaluated if the benefits of VNS may change the long-term outcome of Dravet syndrome.

\section{Conclusions}

Early identification of Dravet syndrome is important to ensure appropriate treatment and to avoid frequent status epilepticus.

Our results suggest that VNS should be considered as an alternative option for patients with medically refractory epilepsy in Dravet syndrome as this may lead to improved seizure control, reduce need for ASMs, and improve quality of life.

Larger prospective multicenter studies are needed to guide patient selection and to study the impact of the type of SCN1A mutation on response to VNS. A better understanding of short- and long-term efficacy of VNS for seizure control, dosing parameters of VNS, response of seizure subtypes to VNS treatment, and its impact on cognition and behavior is needed.

A patient registry would collect data from patients with this rare epilepsy syndrome and lead to improved knowledge on the overall outcome of VNS therapy in Dravet syndrome patients.

\section{References}

1 Martinos MM, Yoong M, Patil S, et al. Early developmental outcomes in children following convulsive status epilepticus: a longitudinal study. Epilepsia 2013;54(6):1012-1019

2 Dravet C. The core Dravet syndrome phenotype. Epilepsia 2011; 52(52, Suppl 2):3-9

3 Dravet C, Bureau M, Dalla Bernardina B, Guerrini R. Severe myoclonic epilepsy in infancy (Dravet syndrome) 30 years later. Epilepsia 2011;52(52, Suppl 2):1-2

4 Brunklaus A, Ellis R, Reavey E, Forbes GH, Zuberi SM. Prognostic, clinical and demographic features in SCN1A mutation-positive Dravet syndrome. Brain 2012;135(Pt 8):2329-2336

5 Chiron C, Marchand MC, Tran A, et al. Stiripentol in severe myoclonic epilepsy in infancy: a randomised placebo-controlled syndrome-dedicated trial. STICLO study group. Lancet 2000; 356(9242):1638-1642

6 Kwan P, Arzimanoglou A, Berg AT, et al. Definition of drug resistant epilepsy: consensus proposal by the ad hoc Task Force of the ILAE Commission on Therapeutic Strategies. Epilepsia 2010;51(6): 1069-1077

7 Coppola G, Capovilla G, Montagnini A, et al. Topiramate as add-on drug in severe myoclonic epilepsy in infancy: an Italian multicenter open trial. Epilepsy Res 2002;49(1):45-48

8 Genton P, Velizarova R, Dravet C. Dravet syndrome: the long-term outcome. Epilepsia 2011;52(52, Suppl 2):44-49

9 Caraballo RH. Nonpharmacologic treatments of Dravet syndrome: focus on the ketogenic diet. Epilepsia 2011;52(52, Suppl 2):79-82

10 Cersósimo RO, Bartuluchi M, De Los Santos C, Bonvehi I, Pomata H, Caraballo RH. Vagus nerve stimulation: effectiveness and tolerability in patients with epileptic encephalopathies. Childs Nerv Syst 2011;27(5):787-792

11 Chieffo D, Battaglia D, Lettori D, et al. Neuropsychological development in children with Dravet syndrome. Epilepsy Res 2011; 95(1-2):86-93

12 Zamponi N, Passamonti C, Cappanera S, Petrelli C. Clinical course of young patients with Dravet syndrome after vagal nerve stimulation. Eur J Paediatr Neurol 2011;15(1):8-14

13 Orosz I, McCormick D, Zamponi N, et al. Vagus nerve stimulation for drug-resistant epilepsy: a European long-term study up to 24 months in 347 children. Epilepsia 2014;55(10):1576-1584 